IZA DP No. 7577

Job Contact Networks and Wages of Rural-Urban Migrants in China

Wenjin Long

Simon Appleton

Lina Song

August 2013 


\title{
Job Contact Networks and Wages of Rural-Urban Migrants in China
}

\author{
Wenjin Long \\ University of Nottingham
}

Simon Appleton

University of Nottingham

and IZA

Lina Song

University of Nottingham

and IZA

\section{Discussion Paper No. 7577 \\ August 2013}

\author{
IZA \\ P.O. Box 7240 \\ 53072 Bonn \\ Germany \\ Phone: +49-228-3894-0 \\ Fax: +49-228-3894-180 \\ E-mail: iza@iza.org
}

Any opinions expressed here are those of the author(s) and not those of IZA. Research published in this series may include views on policy, but the institute itself takes no institutional policy positions. The IZA research network is committed to the IZA Guiding Principles of Research Integrity.

The Institute for the Study of Labor (IZA) in Bonn is a local and virtual international research center and a place of communication between science, politics and business. IZA is an independent nonprofit organization supported by Deutsche Post Foundation. The center is associated with the University of Bonn and offers a stimulating research environment through its international network, workshops and conferences, data service, project support, research visits and doctoral program. IZA engages in (i) original and internationally competitive research in all fields of labor economics, (ii) development of policy concepts, and (iii) dissemination of research results and concepts to the interested public.

IZA Discussion Papers often represent preliminary work and are circulated to encourage discussion. Citation of such a paper should account for its provisional character. A revised version may be available directly from the author. 


\section{ABSTRACT}

\section{Job Contact Networks and Wages of Rural-Urban Migrants in China*}

In nationally representative household data from the 2008 wave of the Rural to Urban Migration in China survey, nearly two thirds of rural-urban migrants found their employment through family members, relatives, friends or acquaintances. This paper investigates why the use of social network to find jobs is so prevalent among rural-urban migrants in China, and whether migrants face a wage penalty as a result of adopting this job search method. We find evidence of positive selection effects of the use of networks on wages. Users of networks tend to be older, to have migrated longer ago and to be less educated. In addition, married workers and those from villages with more out-migrant are more likely to use networks, while those without local residential registration status are less likely. Controlling for selectivity, we find a large negative impact of network use on wages. Using job contacts brings open access to urban employment, but at the cost of markedly lower wages.

JEL Classification: J24, J31, O15

Keywords: $\quad$ social network, job contact, wage, rural-urban migrants, switching regression, China

Corresponding author:

Wenjin Long

School of Contemporary Chinese Studies

Jubilee Campus, University of Nottingham

Nottingham, NG8 1BB

United Kingdom

E-mail: longwenjin@gmail.com

\footnotetext{
* We thank Yanjie Bian, Yucheng Liang, Xiaoyuan Dong and participants at the International Network for Social Network Analysis Conference 2013 and the Brow Bag seminar at School of Contemporary Chinese Studies, University of Nottingham for helpful comments. Financial support from ESRC under Grant RES-238-25-0035 is gratefully acknowledged.
} 


\section{Introduction}

There has been increased interest in the role of social networks and relations in economic development. Following Coleman (1988), "social capital" has been hypothesised to be a determinant of productivity, much as human capital was earlier added to the conventional factors of production (land, labour and capital). Social capital has variously been understood as norms of behaviour such as "trust" that may underpin economic relations or as "networks" of contacts that may provide the valuable economic information. Early empirical studies often found large economic benefits to social capital, for example, for household income in rural Tanzania (Narayan and Pritchett, 1999); for manufacturing productivity in Ghana (Barr, 2000); or agricultural traders in Madagascar (Fafchamps and Minten, 2002). The significant role of job contacts in obtaining employment has long been recognised, although what is less well understood is the possible effects on subsequent wages or labour productivity of using such networks. In this paper, we estimate the effect of using social networks on the wages of migrants in urban China.

Much as the general literature on social capital focussed on productivity benefits, theoretical models of labour markets often predict beneficial effects on wages from using job contacts. In line with the "social capital as networks" interpretation, using job contacts may give job searchers more information about opportunities and ensure a better matching of workers to jobs, translating into higher wages for users of networks (Montgomery, 1991; Mortensen and Vishwanath, 1994). Additionally, following the "social capital as trust" approach, those who find jobs by using contacts may feel additional peer pressure to perform and thus attain higher productivity and wages (Kandel and Lazear, 1992). However, while positive wage effects from using job contacts are sometimes found, this is far from universal and has led to consideration being given as to why using job contacts may appear to lower wages (Delattre and Sabatier, 2007). One explanation centres around training costs (Pellizzari, 2010). Firms may only be able to expend extra effort in using formal means of filling posts (for example, advertising or using recruitment agencies), rather than informal means (using social networks). Consequently, the use of formal means of filling posts will be more common where the costs of the posts remaining unfilled are high, as is likely to be the case with posts with high training costs (and consequent high wages). A second explanation centres around job seeker impatience: those keen to find employment quickly may use job contacts, sacrificing potentially higher wages from better matched posts for quicker entry into work (Bentolila et al., 2010).

Given the ambiguous theoretical predictions about the impact of using job contacts on subsequent wages, it is worthwhile to test the hypothesis empirically. However, while it is straightforward to measure the correlation between the use of 
job contacts and subsequent wages, one must be cautious about drawing causal inferences from this due to unobservables that may affect both use of social networks and labour market outcomes (Mouw, 2006). Users of job contacts typically differ from non-users in various observed characteristics - for example, they are often older. They may also differ in unobserved characteristics. If they are found to have higher (or lower) wages than non-users, the suspicion arises that this may simply reflect higher (or lower) unobserved productivity. In order to control for the possible selectivity of use of job contacts, we employ a switching regression model of wages.

We focus on the impact of using social network on labour market outcomes for rural-urban migrants in China. This is an interesting case to study, not only because rural-urban migration in China is the largest human movement in the history of the world in terms of quantity, but also because migrants in China cannot access to institutional assistance from government at destinations. They are often forced to rely on using their social contacts to find work but the effect of this on labour market outcomes in China is not yet well understood.

Our intention in this study is to answer three main questions. First, what determines whether rural-urban migrants use contacts to find employment? Second, is the use of job contacts endogenous to wages: that is to ask, are the unobservables which influence job search methods related to those which determine wages? Third, what is the causal effect of using job contacts on subsequent wages: do users of networks enjoy higher or lower wages than non-users, ceteris paribus? These questions may have implications for policy - for example, people would question the existence of public employment agencies if social network has a positive impact on job search and wages (Delattre and Sabatier, 2007). Conversely, in the Chinese context, if using networks appears to incur a wage penalty, it may spur policymakers to find ways to increase rural people's access to formal means of finding urban jobs.

The structure of the remainder of the paper is as follows. Section 2 reviews the literature, focusing on the measures of social networks and on methods for identifying their effects on labour market outcomes. Section 3 describes the data and the switching regressions model to be estimated. Section 4 reports descriptive statistics while Section 5 presents the econometric results. Section 6 concludes.

\section{Literature review}

There are a great number of studies on the relationship between the social networks and labour market outcomes. Studies may disagree because they analyse different contexts or use different data-sets. However, they may also disagree for two methodological reasons. First, studies use different proxies to measure social 
networks. Second, studies employ different econometric models to estimate the relation between social networks and labour market outcomes. Consequently, in this section, we will discuss the measures of social network and the econometric methods commonly used in the literature.

\subsection{Measures of social network}

Recent literature has mainly focused on econometric methods and tended to neglect the issue of the measurement of social networks. However, using different measures of social network may result in different estimates of the relation between social networks and labour market outcomes. Obtaining agreement on suitable econometric methods only and ignoring the definition of social network may still lead to incomparable estimates.

Zhang and Li (2003) ) equate guanxi to social networks and define three types of guanxi for migrants: receiving help from relative or family member during the process of finding a job; having contacts outside the region or receiving remittance transactions from non-resident family members; having family member who are cadres.

Giulietti et al. (2010) use direct measures of social network, including both the quality and quantity of contacts. The size of the social network is measured as the total number of people living in cities that the migrant greeted during last Spring Festival. The quality of social network is a dummy variable which equal to 1 if the first supporter is currently employed.

Mouw (2010) uses the number of relatives in the U.S. to measure Hispanic workers' social capital. Wahba and Zenou (2005) use population density as a proxy for the size of social network and use the unemployment rate as a proxy for the quality of social network.

Chen (2011) reviews three kinds of social network: 1) using contacts as social capital, which focuses on the treatment effects of using contacts or social networks on individuals' labour market outcomes; 2) used social capital, which refers to quantity or quality of social resources already mobilized or used from a certain helper(s); 3) accessed social capital or network social capital, which concerns the quantity or quality of the social resources to which the respondent has access.

This study uses the first of Chen's three definitions of social network: the use of contacts to find jobs. This is the most common measure of social networks used in labour market studies and makes our analysis easy readily comparable with the work of other researchers. 


\subsection{Models exploring the relation between social network and wages}

The most common method to explore the relationship between social network and wages is to estimate an Ordinary Least Squares wage equation which includes a explanatory variable that measures social networks (see Aguilera (2005); Granovetter (1973, 1983); Montgomery (1991); Bian (1997) and Zhang and Li (2003). For example, it is common to include in the wage equation a dummy variable that equals to 1 when people use their social network to find jobs. The coefficient of this dummy variable captures the level effect of using social networks. An assumption of this method is the restriction of the coefficient to be the same for users of social network and non-users of social network, which might be not true in reality.

Another problem with OLS estimation is that there might be endogeneity bias, with users of social networks differing from non-users in unobserved characteristics that affect wages. For example, migrants with high skills may be more likely to choose market-methods. Such a bias is to be expected if the use of social network to find a job is correlated with the expectation of labour market outcomes (Giulietti et al., 2011).Omitted variables that are positively correlated with both social network and earnings may lead to overestimation of the effect of networks on wages. This potential endogeneity must be addressed and several methods have been applied to do this.

Random assignment including social and natural experiments is the best way to correct self-selection bias (Mouw, 2006). Beaman and Magruder (2012) create short-term jobs in a laboratory to investigate who gets job referrals. They ask every participant to refer a friend who is most suitable for the job. Thus the type of referral contract and amount offered is randomised and selection bias is avoided. Khan and Lehrer (2013) try to identify the effects of changes of social networks on employment by using the random assignment method.

Using panel data is another way to eliminate unobserved fixed effects (Battu et al., 2011; Yakubovich, 2005). However, the use of panel data may depend on the definition of social network. For example, Knight and Yueh (2008) use Chinese Communist Party membership and the number of close contacts of the respondent as measures of social capital. They admit that panel data might fail to explore the effect of social capital on labour market as CCP membership and the number of close contacts does not vary much over time or may even be time-invariant for many observations.

Where experimental or panel data are not available, endogeneity concerns are typically addressed by modelling the selection process - whether or not migrants use social networks - and building a model of labour market outcomes that controls for the selectivity. Instrumental variable methods (IV), treatment effects model, Heckman's Sample Selection model, endogenous switching regression model, 
propensity score matching (Ye et al., 2012), and structural equation model (SEM) are typical methods to discover the selection process with non-experimental cross sectional data.

With most of these methods, finding an appropriate instrumental variable for the use of social networks on wages is a common problem in practice. The distance from home village to destination might be a potential instrumental variable for social network. However, Zhang and Zhao (2013) argue that migrant wages will be correlated with the distance from home village to destination as migrants face an income-distance trade-off.

Both the treatment effects model and the Heckman selection model are twostage processes. The first stage uses a probit model on the full data. They then calculate an inverse Mills ratio (non-selection hazard rate) for selected samples and (with the treatment effects model) selection hazard rate for unselected samples. The hazard rate variable is then used as an additional regressor in the second stage model of wage determination. Both approaches can be estimated by either the maximum likelihood method or by a two-step method. The difference between the Heckman selection model and the treatment effects model is that the former only uses the selected sample whereas the latter uses the full sample but restricts the use of social networks to have only a shift effect on wages Fraser (2009).

The switching regression uses the Heckman two-stage procedure twice, one for selected sample and the other for the unselected sample. Like the treatment effects model, the switching regression estimates effect of networks on wages directly using the full sample. However, it relaxes the assumption that the effect is only a shift effect and, like the Heckman sample selection model, does not restrict users and non-users to having the same coefficients in the wage equations. Studies using switching regressions include Delattre and Sabatier (2007) and Liang (2010).

In this paper, we use the switching regression approach as the best method for investigating the effect of social networks on wages available for non-experimental cross-sectional data. 


\section{$3 \quad$ Data and methodology}

\subsection{Data}

The empirical analysis is based on the first wave of the Rural to Urban Migration in China survey (RUMIC 2008 ${ }^{1}$ ). This survey was conducted in 2008 and includes approximately 5,000 rural-urban migrant households. Samples were randomly chosen in the fifteen migrant destination cities nationally. The dataset includes detailed information about socio-demographic characteristics, labour market outcomes, health conditions, major life events and social network information. Our analysis is based on 5453 employed migrant workers, aged 16-60 years old.

Our focus in this paper is on real wages, defined to include bonuses, allowances and income in-kind. Results from the survey are reported in Dmurger and Li (2012), Qu and Zhao (2011) and Meng et al. (2010).

Granovetter (1974) notes that individuals may use several methods to find a job and only one method leads to success. But the dataset we use only ask the main source of job finding. The dataset does not have variables about information flows between employers, contacts, and employees, so we are limited in what we can analyse about the process of job search.

\subsection{Endogenous Switching Regression Model}

The endogenous switching regression is used to estimate the relation between using of social network and wages, controlling for self-selection bias. The endogenous switching regression can predict the expected outcome for users of social network who self-selected in to non-users of social network and vice versa (Dutoit, 2007; Lokshin and Sajaia, 2004; Powers, 2007). This methods has proved to be useful in dealing with endogeneity from self-selection by Adamchik and Bedi (2000) and Heitmueller (2006). OLS regression and treatment effects model will also be estimated to give comparisons and gauge robustness.

Let $Z^{*}$ denote a latent variable for the propensity to use social networks with the following index function:

$$
\begin{gathered}
Z^{*}=W \gamma+v, \quad v \sim N\left(0, \sigma_{v}^{2}\right) \\
Z=1 \quad \text { if } \quad Z^{*}>0, Z=0 \text { otherwise }
\end{gathered}
$$

\footnotetext{
${ }^{1}$ The Longitudinal Survey on Rural Urban Migration in China (RUMiC) consists of three parts: the Urban Household Survey, the Rural Household Survey and the Migrant Household Survey. It was initiated by a group of researchers at the Australian National University, the University of Queensland and the Beijing Normal University and was supported by the Institute for the Study of Labor (IZA), which provides the Scientific Use Files. The financial support for RUMiC was obtained from the Australian Research Council, the Australian Agency for International Development (AusAID), the Ford Foundation, IZA and the Chinese Foundation of Social Sciences.
} 
where $Z=1$ if the individual chooses social networks to find a job and $Z=0$ otherwise. $Z^{*}$ can be estimated using models for binary data. Let $Y_{1}$ be the earnings for users of social networks and let $Y_{0}$ be the earnings for non-users of social networks.

$$
Y_{1}=X_{1} \beta_{1}+\mu_{1}, \quad \mu_{1} \sim N\left(0, \sigma_{1}^{2}\right) \quad \text { if } \quad Z=1
$$

and

$$
Y_{0}=X_{0} \beta_{0}+\mu_{0}, \quad \mu_{0} \sim N\left(0, \sigma_{0}^{2}\right) \quad \text { if } \quad Z=0
$$

That is, we observe $Y_{1}$ when $Z=1$, in which case $Y_{0}$ is unobserved, latent, or missing. Similarly, we observe $Y_{0}$ when $Z=0$, in which case $Y_{1}$ is missing. Note that in practice, we observe sample respondents in only one state $Z=1$ or $Z=0$.

Assume that $v, \mu_{1}, \mu_{0}$ have a trivariate normal distribution with mean vector zero and covariance matrix:

$$
\Omega=\left[\begin{array}{ccc}
\sigma_{v}^{2} & \sigma_{1 v} & \sigma_{0 v} \\
\sigma_{1 v} & \sigma_{1}^{2} & \cdot \\
\sigma_{0 v} & \cdot & \sigma_{0}^{2}
\end{array}\right]
$$

where $\sigma_{v}^{2}$ is a variance of the error term in the selection equation. We can assume that $\sigma_{v}^{2}=1 . \sigma_{1}^{2}$ and $\sigma_{0}^{2}$ are variances of the error terms in the wage equations. $\sigma_{1 v}$ is a covariance of $\mu_{1}$ and $v$, and $\sigma_{0 v}$ is a covariance of $\mu_{0}$ and $v$. The covariance between $\mu_{1}$ and $\mu_{0}$ is not defined, as $Y_{1}$ and $Y_{0}$ are never observed simultaneously.

The model presented above is referred to as an endogenous switching regressions model. It is used to address issues of self-selection.

Using direct maximum likelihood methods, the log-likelihood function associated with our model is written as

$$
\begin{aligned}
\log L & =\sum_{Z=1}\left[\log \Phi\left(\eta_{1}\right)-\frac{1}{2}\left\{\log \left(2 \pi \sigma_{1 v}\right)-\left(\frac{Y-X \beta_{1}}{\sigma_{1}}\right)^{2}\right\}\right] \\
& +\sum_{Z=0}\left[\log \Phi\left(\eta_{0}\right)-\frac{1}{2}\left\{\log \left(2 \pi \sigma_{0 v}\right)-\left(\frac{Y-X \beta_{0}}{\sigma_{0}}\right)^{2}\right\}\right]
\end{aligned}
$$

where

$$
\eta_{1}=\frac{W \gamma+\left(Y-X \beta_{1}\right) \sigma_{1 v} / \sigma_{1}^{2}}{\sqrt{1-\rho_{1 v}^{2}}}
$$

and 


$$
\eta_{0}=\frac{W \gamma+\left(Y-X \beta_{0}\right) \sigma_{0 v} / \sigma_{0}^{2}}{\sqrt{1-\rho_{0 v}^{2}}}
$$

Note:

$\rho_{0 v}=\frac{\sigma_{0 v}^{2}}{\sigma_{0} \sigma_{v}}=\frac{\sigma_{0 v}}{\sigma_{0}}$ is the correlation coefficient between $\mu_{0}$ and $v$.

$\rho_{1 v}=\frac{\sigma_{1 v}^{2}}{\sigma_{1} \sigma_{v}}=\frac{\sigma_{1 v}}{\sigma_{1}}$ is the correlation coefficient between $\mu_{1}$ and $v$.

$\phi($.$) is the standard normal density function.$

$\Phi($.$) is the standard normal cumulative distribution function.$

After estimating the models parameters, the following unconditional expectations could be calculated:

$$
\begin{aligned}
& E\left(Y_{1} \mid Z=1\right)=X_{1} \beta_{1} \\
& E\left(Y_{0} \mid Z=0\right)=X_{0} \beta_{0}
\end{aligned}
$$

Because of the selection problem (the failure to observe $Y_{0}$ when $Z=1$ and the failure to observe $Y_{1}$ when $Z=0$ ), we need to write these outcomes in a selection-equation format. Taking expectations of the outcome equations, we can find the expected earnings for a user of social networks who self-selected into user of social networks as follows:

$$
\begin{aligned}
E\left(Y_{1} \mid Z=1, X_{1}\right) & =E\left(Y_{1} \mid Z^{*}>0\right) \\
& =E\left(Y_{1} \mid W \gamma+v>0\right) \\
& =X_{1} \beta_{1}+E\left(\mu_{1} \mid v<W \gamma\right) \\
& =X_{1} \beta_{1}+\sigma_{1} \rho_{1 v} \frac{\phi(W \gamma)}{\Phi(W \gamma)}
\end{aligned}
$$

Where $\frac{\phi(W \gamma)}{\Phi(W \gamma)}$ is referred to as non-selection hazard rate or the inverse Mills ratio.

Similarly, the expected earnings for a non-user of social networks who selfselected into non-user of social networks is:

$$
\begin{aligned}
E\left(Y_{0} \mid Z=0, X_{0}\right) & =E\left(Y_{0} \mid Z^{*}<0\right) \\
& =E\left(Y_{0} \mid W \gamma+v<0\right) \\
& =X_{0} \beta_{0}+E\left(\mu_{0} \mid v>W \gamma\right) \\
& =X_{0} \beta_{0}-\sigma_{0} \rho_{0 v} \frac{\phi(W \gamma)}{1-\Phi(W \gamma)}
\end{aligned}
$$


Where $\frac{\phi(W \gamma)}{1-\Phi(W \gamma)}$ is referred to as selection hazard rate.

In the experimental literature, there is the notion that those assigned to status 1 are identical to those assigned to status 0 , so that there is an interchangeability across statuses. It then makes sense to ask what the outcome would be if a respondent in status 1 were assigned to status 0 and vice versa. Next we examine how we might evaluate the expected earnings if individuals were assigned to statuses other than the ones they in fact entered. The expected outcome for user of social networks if they would have been non-user of social networks is:

$$
\begin{aligned}
E\left(Y_{1} \mid Z=0, X_{1}\right) & =E\left(Y_{1} \mid Z^{*}<0\right) \\
& =E\left(Y_{1} \mid W \gamma+v<0\right) \\
& =X_{1} \beta_{1}+E\left(\mu_{1} \mid v>W \gamma\right) \\
& =X_{1} \beta_{1}-\sigma_{1} \rho_{1 v} \frac{\phi(W \gamma)}{1-\Phi(W \gamma)}
\end{aligned}
$$

Similarly, the expected outcome for non-users of social networks had they been users of social networks would be:

$$
\begin{aligned}
E\left(Y_{0} \mid Z=1, X_{0}\right) & =E\left(Y_{0} \mid Z^{*}>0\right) \\
& =E\left(Y_{0} \mid W \gamma+v>0\right) \\
& =X_{0} \beta_{0}+E\left(\mu_{0} \mid v<W \gamma\right) \\
& =X_{0} \beta_{0}+\sigma_{0} \rho_{0 v} \frac{\phi(W \gamma)}{\Phi(W \gamma)}
\end{aligned}
$$

We can use Stata command movestay to estimate this endogenous switching regression with consistent standard errors by using the full-information maximum likelihood method (Lokshin and Sajaia, 2004).

\section{Descriptions}

\subsection{Job Search Methods}

Employed individual migrant workers were asked about the main job search method used in finding their current jobs. The survey provides an extensive list of job search methods as listed in Table 1.

Introduced by friends is the predominant method of finding information of about jobs. 31 percent of the respondents use this methods. The second most common job search method is through relatives (21 percent); 7.57 percent of respondents use family members and 2.92 percent use acquaintances; 2.75 percent find jobs from other categories. 
The job search methods in Table 1 can be grouped into four. The firs group is though the government agents, including: assignment by the government; through employment agent run by government; and through community employment service station. The second is through market competition including: through commercial employment agents run by private owners (including in the job fairs); application to job advertisement; applying directly to the employers; and employer's direct recruitment. The third group is through social networks, including: introduced by family members; introduced by relatives; introduced by friends; and introduced by acquaintance. The fourth group is a residual category for getting jobs from other sources not specified above ${ }^{2}$.

Table 2 shows that almost two thirds of all migrants obtain their current jobs through social networks consist of family members, relatives, friends, and acquaintances. Only 2 percent get jobs through the government. And 33 percent compete for jobs in the labour market ${ }^{3}$.

To simplify analysis, we merge users of the government, market and others methods into one group we label non-users of network. As Table 3 shows, users of network are nearly twice as numerous as non-users of network.

\subsection{Homophily}

The difference in personal characteristics between users and non-users of network is shown in Table 4. Older and less educated people are more likely to use social network to find jobs while the young and educated tend to find jobs through the market, the government and other channels. This shows that the use of social networks is not random and thus may be endogenous to wages. Gender differences between users of network and non-users of network are small. Married people are more likely to use social networks than unmarried people.

\subsection{Job Search Methods and Wages}

In our analysis, we model the impact of using social networks on hourly wages. In the whole sample, the average hourly wage is about 5.63 yuan. Migrant workers who use social networks average 0.63 yuan lower wages per hour than their counterparts who do not.

\footnotetext{
${ }^{2}$ Granovetter (1974) divides job search methods into three groups: formal means, personal contracts, and direction application. He argues direction application that does not use a formal or personal intermediary is different from both formal means and from personal contacts.

${ }^{3}$ We only asked migrants to identify the final way of job search which secured them their current job. Where they used multiple means of job search, they were asked to report the final decisive method.
} 
From the kernel density graph of log of hourly wage is shown in Figure 1, we can see that the distribution of earnings for users of networks is to the left of that for users

\section{Models for Job Search Methods and Wages}

\subsection{OLS regressions}

Our estimations start with OLS regressions on wage rate. The explanatory variables we control for are divided into personal characteristics, job related characteristics and a set of dummy variables for provinces. Personal characteristics include gender, age, age squared, years of migration, years of migration squared, and years of schooling. Job related characteristics include occupation, industry, ownership sector and firm size.

Our focus is on whether using networks to find jobs has an impact on the wages you subsequently earn from that job. From the OLS regressions in table 6 , the magnitude of the coefficient is small, implying the use of social networks is associated with $1 \%$ lower wages, ceteris paribus. Moreover, the coefficient is not statistically significant; using OLS, we cannot reject the null hypothesis that network use has no effect on wages.

\subsection{Switching regression}

Since OLS estimates may be biased due to self-selection over the use of social networks, we run a switching regression instead. The key issue in controlling for the endogeneity of social networks is identification: finding instrumental variables that could be included in the selection model and excluded from the wage equation. Delattre and Sabatier (2007) use parental occupation and ease of access to public employment agencies to identify the effect of using social networks on wages in France in $1995^{4}$.

From the variables we have in the dataset, we use marriage status, ratio of migrants in the home village and hukou status as identifying variables. Married workers may have access to a wider network of contacts, via their spouses, encouraging the use of networks (Wang, 2013). Ye and Zhou (2010) suggest that marriage does not affect migrant earnings directly because most migrants are working on

\footnotetext{
${ }^{4}$ Liang (2010) uses a switching regression model to estimate the effect of using social networks to find employment on wages in eight cities in China. Their exclusion restriction is to use the square of the age at which workers obtained their jobs in the selection model but not in the wage equations. This exclusion restriction seems a questionable a priori given that they include the linear term for age at which workers obtain their jobs in both the selection and wage equations.
} 
less skilled jobs. Where there is a large proportion of rural-urban migrants being sent from the worker's home village, workers in that village are likely to have more contacts who can help them find urban jobs. Hence we follow Chen (2009) and Chen et al. (2010) in using the proportion of labour migrants in the home village as an indicator of the village social network. When the household registration (hukou) of the worker is not local, they may have fewer contacts with local people and thus less chance of using their networks to find employment. We assume that these identifying variables influence the selection choice to use social networks but not impact wages directly (assumptions that we test empirically).

Age, age squared, years of migration, years of migration squared, and educational level are included in selection model.

The selection model from Table 7 shows that each of three hypothesised identifying variables have significant effects on the likelihood of using social networks to find employment, with the predicted signs. Amongst the other control variables, the use of social networks declines with education level and increases with age and with years of migration. Older workers are likely to have accumulated more acquaintances and thus have access to a wider social network. Educated workers may have less need to use social networks to find jobs, as their qualifications give them an edge in job competition.

Table 8 shows the results of wage equations from the switching regressions. The rho values in Table 8 , which measure the correlation coefficients between the error terms in the selection model and the wage equation, are both statistically significant. This implies that the use of social network is endogenous to wage determination. Thus the switching regression is more appropriate than the OLS regression. The rho term of non-users of networks, corresponds to $\rho_{0 v}$ discussed earlier: its positive value implies that unobserved factors $v$ which increase the likelihood of using social networks are positive correlated with the unobserved determinants $\mu_{0}$ of the wages of those not using networks. Similarly, the positive value of the rho term for users of networks, corresponds to $\rho_{1 v}$ and implies $v$ is positively correlated with the unobserved determinants $\mu_{1}$ of the wages of those using networks. There is thus positive selection in network use-those who use social networks are likely to be paid more due to unobservable factors. Note that this positive selectivity is present in both regimes - users of networks have unobservables that would imply higher wages conditional on using networks, but also conditional on not using networks. This implies that users of networks tend to have unobserved characteristics ("ability") that raise wages, or perhaps to work in jobs with unobserved characteristics that are associated with higher pay. Not controlling for this, for example in the OLS models, will bias upwards estimates of the impact of network usage on wages. Delattre and Sabatier (2007) obtained the same finding when analysing data from France in 1995. 
The switching regression model differs from an endogenous dummy variable model in allowing explanatory variables to impact wages differently between users of network and non-users of network. However, comparing the wage equations for users of networks and for non-users, few differences are apparent. Generally, speaking the determinants of wages appear similar in the two sub-samples. Wald tests for differences in the individual coefficients reveal no differences in the explanatory variables that are statistically significant at the $5 \%$ level. The coefficients on age and age squared are each significant different in the two samples at the $10 \%$ level. Plotting the joint effects of the age quadratics, it is apparent that wages fall with age at a faster rate for users of networks than for non-users. The constant terms in the two wage equations are significantly different from each other at the $1 \%$ level, suggesting wage differences between the two sub-samples.

\subsection{Wage difference}

Table 9 compares the predicted log wages from the wage equations in Table 8 with the observed values. Unconditional log wages are predicted from the switching model using equation 1 and 2. Conditional log wages are predicted from the switching model using equation $3,4,5$ and 6 . The predicted unconditional log wages are the most useful for calculating the effect of using social networks on wages, since they are not subject to any selectivity bias.

Non-users of networks have somewhat higher observed mean log wages than users, implying a wage differential of around $9 \%$. However, the gap in unconditional predicted mean wages is much greater, consistent with a wage differential of around $59 \%$. This reflects the positive selectivity of network use - network users have unobservable factors that raise their wages and thus the observed wage gaps masks the extent of the negative effect of using networks to find jobs on wages.

It is not uncommon in the literature to find wage discounts from using social networks. However, what is striking about our results is the magnitude of the effect. For example, Delattre and Sabatier (2007) find a 7\% wage discount in France in 1995. Bentolila et al. (2010) report discounts of at least $2.5 \%$ in the EU and US. While of the same sign, the wage differentials we estimate for rural-urban migrants in China are of an order of magnitude higher than those found in industrialised countries. We can only speculate on why the wage discount from using social networks is so much higher in China, but one factor is likely to be the large ruralurban gap in labour productivity in China. Potential rural-urban migrants may be faced with a choice between staying in low return agriculture or finding a much more remunerative non-agricultural job if they migrate. It is not uncommon to find estimates of labour productivity outside of agriculture being ten times as high as in agriculture (Knight and Song, 2003). In such a situation, it is quite plausible that rural workers will accept a sizable urban wage discount from using networks, 
if that gives them access to urban jobs.

\subsection{Robustness tests}

\section{OID test}

In our selection model, we use three identifying instrumental variables: marriage status, the ratio of labour migrants in home village and hukou status. We assume these three instrumental variables only effect wages through network use. We test this assumption by an over-identifying test for instrumental variables in Table 10. The dependent variable is the residual of wage equation from the switching regressions. The independent variables are all the exogenous regressors in the wage equations together with the three instrumental variables. This auxiliary regression shows that all the instrumental variables do not affect the residuals of the wage equations, so we cannot reject our assumption that they can be excluded from the wage equations.

In preliminary work, we explored various other potential instruments for network usage, including family political background, parental education, parental occupation, number of siblings, number of friends living in urban areas and the distance from home province to working province. However, these were rejected as instruments either because they were not correlated with network user or because they were correlated with wage residuals from the switching regressions. Specifically, although family political background is a good IV in Zhang and Lu (2009), it is not correlated with the use of networks in our data. Likewise, parents' education and occupation are not significantly correlated with the use of network. The number of siblings, the number of friends living in city and the distance from the home province to the workplace province are correlated with the use of network, but fail the OID test.

\section{Treatment effects models}

An alternative to the switching regressions approach is to use a treatment effects model, in which use of social networks in job search is included as an endogenous dummy variable in a wage equation. Both Maximumum Likelihood (ML) and two-step estimators imply the dummy variable has a large, significant negative impacts on wages. The coefficient implies use of networks would lower log wages by 0.438 points. This is of a similar order of magnitude to that implied by a comparison of the predicted unconditional mean log wages from the switching regression models. 


\section{Job change}

There might be a difference in the selectivity of network use between migrants who still hold their first jobs and those who changed their jobs. Migrants who rely more on social network to find their first migrant jobs may be totally unfamiliar with the environment when they come to cities. So we divide all sample into two groups: those who still hold their first jobs and those who changed their jobs We run the same switching regression for both of them. Table 12 reveals that selectivity bias between network use and wage equation exists for both first job holders and for migrants who changed their jobs. This indicates the contingency of the effect of social network on wages. However, the selectivity bias for non-network users is much lower in people changed jobs than for first job holders. Thus the unconditional wage gap between users of network and non-users of network is smaller for migrants changed jobs than that for first job holders.

\section{Conclusion}

It is well understood that social networks play an important role in labour markets, with many people finding jobs through their friends, acquaintances and relatives. In our survey of rural-urban migrants in China in 2008, nearly two thirds found their employment by such job contacts. However, what is less clear is the impact of such job search mechanisms on subsequent wages. Addressing this issue in a convincing manner requires explicit consideration of the selection process which determines whether or not workers use social networks to find their jobs and whether this causes any selectivity bias for wages.

In this paper, we model the selection of job search methods. We find that users of networks to find jobs tended to be older, to have been migrants for longer and to be less educated. In addition, married workers and those from villages which sent out many migrants were more likely to use networks, while those with non-local household registration were less likely. The last three effects - marital status, migration rates in home village and household registration - were used as instrumental variables to identify the impact of network use on wages.

We find evidence of positive selection effects between use of networks and wages. Those using networks to find their jobs appear to have unobservables that are associated with higher pay - this could be unobserved personal characteristics such as ability or perhaps remunerative job characteristics. Thus, although users of networks are less educated than non-users, they appear to have other, unobserved advantages for pay determination. This implies that simple estimations of the impact of network use on migration that do not control for selectivity are upwards biased - benefits would be ascribed to networks that more properly reflect the 
favourable unobserved characteristics of network users.

Controlling for selectivity, we find a large negative impact of network use on wages. Using job contacts brings benefits in terms of giving people from rural China access to urban employment. However, it also imposes a substantial cost - those urban jobs found using job contacts pay markedly less than those found by impersonal means. This negative effect of using employment has been found before, using comparable methods, in industrialised countries. However, what is striking about our results is the magnitude of the effect. This may be explicable given the greater segmentation of labour in China and the consequent large gap in labour productivity between agriculture and the employment of rural-urban migrants. At first look it appears a puzzle, why so many rural-urban migrants use friends and relatives to find jobs if they face a wage penalty as a result. However, such migrants may have less chance of finding jobs if they rely on formal means of job search. Given the large gap in labour productivity rural and urban areas, it may well be worth accepting a wage discount by using social networks if it is the means by which the migrants can escape low return farming and find more remunerative work in urban areas. A potential policy implication of this is that efforts to increase the access of rural people to urban employment through more formal means - labour exchanges, rural recruitment etc. - may well bring large benefits to them in terms of higher wages. 


\section{References}

Adamchik, V. A. and Bedi, A. S. (2000), 'Wage differentials between the public and the private sectors: evidence from an economy in transition', Labour Economics $7(2), 203-224$.

Aguilera, M. B. (2005), 'The impact of social capital on the earnings of puerto rican migrants', The Sociological Quarterly 46(4), 569-592.

Barr, A. (2000), 'Social capital and technical information flows in the ghanaian manufacturing sector', Oxford Economic Papers 52(3), 539-559.

Battu, H., Seaman, P. and Zenou, Y. (2011), 'Job contact networks and the ethnic minorities', Labour Economics 18(1), 48-56.

Beaman, L. and Magruder, J. (2012), 'Who gets the job referral? evidence from a social networks experiment', American Economic Review 102(7), 3574-93.

Bentolila, S., Michelacci, C. and Suarez, J. (2010), 'Social contacts and occupational choice', Economica 77(305), 20-45.

Bian, Y. (1997), 'Bringing strong ties back in: Indirect ties, network bridges, and job searches in china', American Sociological Review 62(3), 366-385.

Chen, Y. (2009), Network effects among rural-to-urban migrants in china, Sociology Working Papers 2009-06, Department of Sociology, Oxford University.

Chen, Y. (2011), 'The causal effect of social capital in the labor market identification challenges and strategies', Chinese Sociological Review 44(2), 25.

Chen, Y., Jin, G. Z. and Yue, Y. (2010), Peer migration in china, Working Paper 15671, National Bureau of Economic Research.

URL: http://www.nber.org/papers/w15671

Coleman, J. S. (1988), 'Social capital in the creation of human capital', American Journal of Sociology 94, S95-S120.

Delattre, E. and Sabatier, M. (2007), 'Social capital and wages: An econometric evaluation of social networking's effects', LABOUR 21(2), 209-236.

Dmurger, S. and Li, S. (2012), Migration, remittances and rural employment patterns: Evidence from china, Working Papers halshs-00744438, HAL. 
Dutoit, L. C. (2007), Heckman selection model, endogenous and exogenous switching models, a survey, Working paper.

URL: http://works.bepress.com/laure_dutoit/3/

Fafchamps, M. and Minten, B. (2002), 'Returns to social network capital among traders', Oxford Economic Papers 54(2), 173-206.

Fraser, S. G. M. W. (2009), Propensity Score Analysis: Statistical Methods and Applications, Sage Publications.

Giulietti, C., Guzi, M., Zhao, Z. and Zimmermann, K. F. (2010), Social networks and the labour market outcomes of rural to urban migrants in china, Working paper.

URL: www.iza.org/conference_files/ReLabEco2010/guzi_m5347.pdf?

Giulietti, C., Schlutery, C. and Wahba, J. (2011), Migrants and social networks: Old ideas, lasting myths and new findings, Working paper.

URL: www.iza.org/conference_files/Transatlantic2011/giulietti_c5931.pdf?

Granovetter, M. (1983), 'The strength of weak ties: A network theory revisited', Sociological Theory 1, 201-233.

Granovetter, M. S. (1973), 'The strength of weak ties', The American Journal of Sociology 78(6), 1360-1380.

Granovetter, M. S. (1974), Getting A Job: A Study of Contacts and Careers, Harvard University Press, Cambridge.

Heitmueller, A. (2006), 'Public-private sector pay differentials in a devolved scotland', Journal of Applied Economics 9(2), 295-323.

Kandel, E. and Lazear, E. P. (1992), 'Peer pressure and partnerships', Journal of Political Economy 100(4), pp. 801-817.

Khan, A. Q. and Lehrer, S. F. (2013), The impact of social networks on labour market outcomes: New evidence from cape breton, Working Paper 18786, National Bureau of Economic Research.

Knight, J. and Song, L. (2003), 'Chinese peasant choices: Migration, rural industry or farming', Oxford Development Studies 31(2), 123-148.

Knight, J. and Yueh, L. (2008), 'The role of social capital in the labour market in china', Economics of Transition 16(3), 389-414. 
Liang, Y. (2010), 'Is social capital and social networks useless?', Sociological Studies $(5)$.

Lokshin, M. and Sajaia, Z. (2004), 'Maximum likelihood estimation of endogenous switching regression models', The Stata Journal 4(3), 10.

Meng, X., Kong, S. T. and Zhang, D. (2010), How much do we know about the impact of the economic downturn on the employment of migrants?, ADBI Working Papers 194, Asian Development Bank Institute.

Montgomery, J. D. (1991), 'Social networks and labor-market outcomes: Toward an economic analysis', The American Economic Review 81(5), 1408-1418.

Mortensen, D. T. and Vishwanath, T. (1994), 'Personal contacts and earnings: It is who you know!', Labour Economics 1(2), 187-201.

Mouw, T. (2006), 'Estimating the causal effect of social capital: A review of recent research', Annual Review of Sociology 32(1), 79-102.

Mouw, T. (2010), The use of social networks among hispanic workers: An indirect test of the effect of social capital, Working paper.

URL: http://www.unc.edu/tedmouw/papers/hispcontacts.pdf

Narayan, D. and Pritchett, L. (1999), 'Cents and sociability: Household income and social capital in rural tanzania', Economic Development and Cultural Change 47(4), pp. 871-897.

Pellizzari, M. (2010), 'Do friends and relatives really help in getting a good job?', Industrial and Labor Relations Review 63(3), 494-510.

Powers, D. (2007), Censored regression, sample selection, endogenous switching, and treatment-effect regression models, Working paper.

URL: http://www.oir.pku.edu.cn/umich/teaching/download/20092/CDAcoursematerials/handouts/Se

Qu, Z. F. and Zhao, Z. (2011), Evolution of the chinese rural-urban migrant labor market from 2002 to 2007, IZA Discussion Papers 5421, Institute for the Study of Labor (IZA).

Wahba, J. and Zenou, Y. (2005), 'Density, social networks and job search methods: Theory and application to egypt', Journal of Development Economics 78(2), 443473.

Wang, S.-Y. (2013), 'Marriage networks, nepotism, and labor market outcomes in china', American Economic Journal: Applied Economics 5(3), 91-112. 
Yakubovich, V. (2005), 'Weak ties, information, and influence: How workers find jobs in a local russian labor market', American Sociological Review 70(3), 408421.

Ye, J., Bo, S., Liu, C. and Zhou, Y. (2012), 'The levels of social network and wage of rural-urban migrants:from a perspective of indentity model', Economic Review (4), 31-42.

Ye, J. and Zhou, Y. (2010), 'Socail captial transformation and migrants' wage- evidence from an survey in beijing', Management World (10), 34-46.

Zhang, J. and Zhao, Z. (2013), Measuring the income-distance tradeoff for ruralurban migrants in china, IZA Discussion Papers 7160, Institute for the Study of Labor (IZA).

Zhang, X. and Li, G. (2003), 'Does guanxi matter to nonfarm employment?', Journal of Comparative Economics 31(2), 315-331.

Zhang, Y. and Lu, M. (2009), 'Whether rural-urban migrants' social network improve their salary?', Management World (3), 45-54. 
Table 1: Composition of Job Search Methods

\begin{tabular}{lrr}
\hline Job search methods & Frequency & Percent \\
\hline Assigned by the government & 30 & 0.55 \\
Through employment agent run by government & 52 & 0.95 \\
Through community employment service station & 37 & 0.68 \\
Through commercial Employment agent run by private & 316 & 5.79 \\
Applied for advertised job & 395 & 7.24 \\
Applied directly & 613 & 11.24 \\
Introduced by family members & 413 & 7.57 \\
Introduced by relatives & 1145 & 21.00 \\
Introduced by friends & 1696 & 31.10 \\
Introduced by acquaintance & 159 & 2.92 \\
Employer recruitment & 447 & 8.20 \\
Other (please specify) & 150 & 2.75 \\
\hline Total & 5453 & 100 \\
\hline
\end{tabular}

Table 2: Regrouped Composition of Job Search Methods

\begin{tabular}{lrr}
\hline Job search methods & Frequency & Percent \\
\hline Through the government & 119 & 2.18 \\
Through the market & 1,771 & 32.48 \\
Through social network & 3,413 & 62.59 \\
Other methods & 150 & 2.75 \\
\hline Total & 5453 & 100 \\
\hline
\end{tabular}


Table 3: Users of network and non-users of network

\begin{tabular}{lrr}
\hline Job search methods & Frequency & Percent \\
\hline users of network & 3413 & 62.59 \\
non-users of network & 2040 & 37.41 \\
\hline Total & 5453 & 100 \\
\hline
\end{tabular}

Table 4: Individual Attributes and Networks Use (in per cent)

\begin{tabular}{lccc}
\hline & non-users of network & Users of network & Total \\
\hline Female & 42.25 & 42.43 & 42.36 \\
Male & 57.75 & 57.57 & 57.64 \\
Married & 52.99 & 60.01 & 57.38 \\
Unmarried & 47.01 & 39.99 & 42.62 \\
& & & \\
Age 16-25 & 45.54 & 40.2 & 42.2 \\
Age 26-35 & 28.53 & 28.77 & 28.68 \\
Age 36-45 & 20.05 & 22.21 & 21.4 \\
Age 46 and above & 5.88 & 8.82 & 7.72 \\
Elementary school or blew & 10.1 & & \\
Junior middle school & 48.77 & 14.7 & 12.98 \\
Senior middle school & 20.83 & 58.16 & 54.64 \\
Specialized secondary or above & 20.29 & 16.87 & 18.36 \\
\hline
\end{tabular}

Table 5: Wages for users of network and non-users of network

\begin{tabular}{lllrll}
\hline & $\mathrm{N}$ & \multicolumn{2}{c}{ hourly wage } & \multicolumn{2}{c}{ log hourly wage } \\
& & Mean & SD & Mean & SD \\
\hline non-users of network & 2030 & 6.02 & 3.96 & 1.73 & 0.54 \\
users of network & 3389 & 5.39 & 3.39 & 1.63 & 0.50 \\
Total & 5419 & 5.63 & 3.62 & 1.67 & 0.52 \\
\hline
\end{tabular}




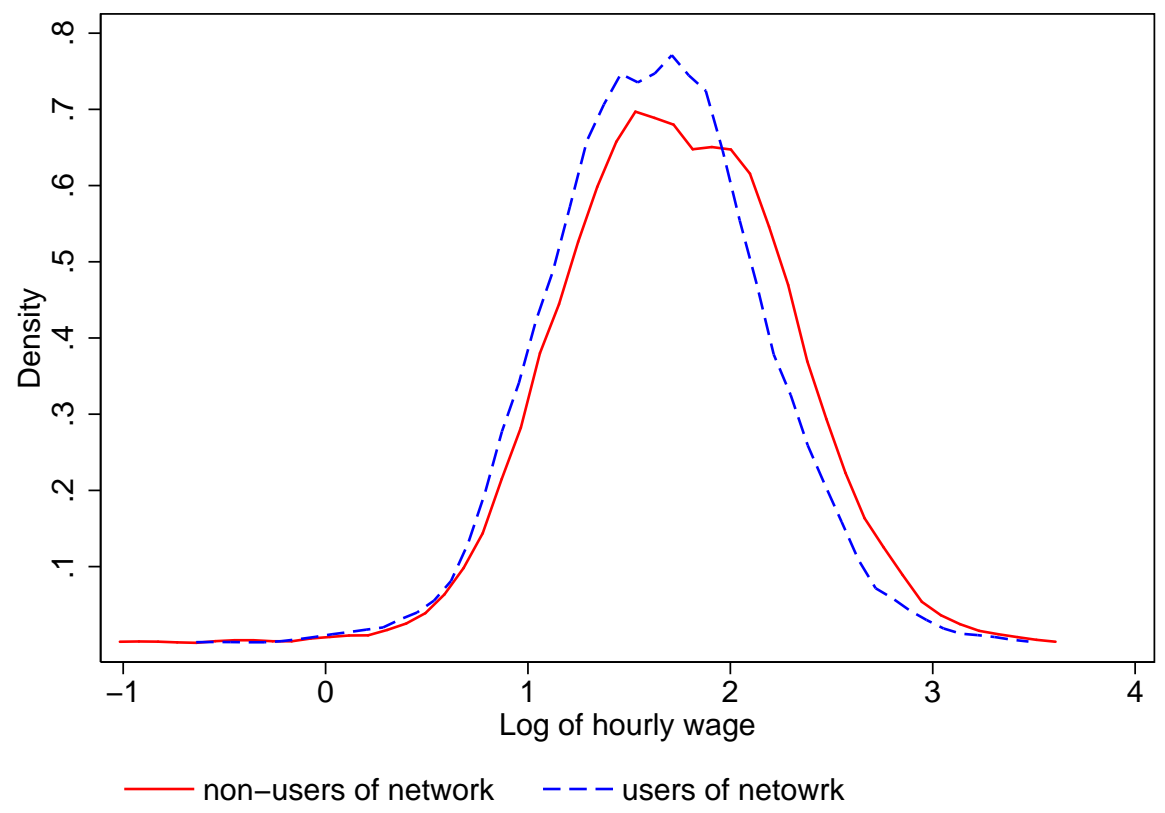

Figure 1: Kernel density graph of log of hourly wage 
Table 6: Wage equations: OLS regressions

\begin{tabular}{|c|c|c|c|c|c|c|}
\hline & \multicolumn{2}{|c|}{ All Sample } & \multicolumn{2}{|c|}{ non-users of network } & \multicolumn{2}{|c|}{ Users of network } \\
\hline & Coef. & SE & Coef. & $\mathrm{SE}$ & Coef. & SE \\
\hline Users of network & -0.0091 & 0.0135 & & & & \\
\hline age & $0.0417^{* * *}$ & 0.0047 & $0.0294^{* * *}$ & 0.0085 & $0.0477^{* * *}$ & 0.0057 \\
\hline age squared & $-0.0647^{* * *}$ & 0.0068 & $-0.0481^{* * *}$ & 0.0124 & $-0.0729^{* * *}$ & 0.0081 \\
\hline years of migration & $0.0218^{* * *}$ & 0.0035 & $0.0316^{* * *}$ & 0.0055 & $0.0174^{* * *}$ & 0.0042 \\
\hline years of migration squared & $-0.0478^{* * *}$ & 0.0126 & $-0.0823^{* * *}$ & 0.0181 & $-0.0322^{* *}$ & 0.0153 \\
\hline male & $0.1096^{* * *}$ & 0.0130 & $0.0841^{* * *}$ & 0.0223 & $0.1283^{* * *}$ & 0.0160 \\
\hline years of schooling & $0.0424^{* * *}$ & 0.0027 & $0.0500^{* * *}$ & 0.0048 & $0.0372^{* * *}$ & 0.0034 \\
\hline \multicolumn{7}{|c|}{ Occupation: base group=White collar } \\
\hline Blue collar & $-0.1953^{* * *}$ & 0.0247 & $-0.2360^{* * *}$ & 0.0360 & $-0.1470^{* * *}$ & 0.0342 \\
\hline other occupation & -0.1643 & 0.1012 & -0.0748 & 0.1460 & -0.1961 & 0.1330 \\
\hline \multicolumn{7}{|c|}{ Industry: base group=manufactory } \\
\hline construction & $0.1204^{* * *}$ & 0.0240 & $0.1506^{* * *}$ & 0.0465 & $0.1141^{* * *}$ & 0.0281 \\
\hline $\begin{array}{l}\text { Electricity, gas, water, } \\
\text { transportation and IT }\end{array}$ & 0.0217 & 0.0331 & -0.0073 & 0.0544 & 0.0476 & 0.0418 \\
\hline Commerce and trade & 0.0091 & 0.0228 & 0.0191 & 0.0413 & 0.0112 & 0.0271 \\
\hline Restaurant and catering & $-0.1232^{* * *}$ & 0.0210 & $-0.1361^{* * *}$ & 0.0340 & $-0.1046^{* * *}$ & 0.0266 \\
\hline Finance, estate, & -0.0374 & 0.0236 & -0.0158 & 0.0395 & -0.0421 & 0.0293 \\
\hline services & $-0.0626^{* *}$ & 0.0266 & -0.0636 & 0.0445 & -0.0490 & 0.0331 \\
\hline \multicolumn{7}{|c|}{ Ownership: base group=state and collective } \\
\hline Private enterprises & $-0.0477^{* *}$ & 0.0223 & $-0.0724^{*}$ & 0.0410 & -0.0367 & 0.0263 \\
\hline Self-employed Individuals & $-0.0790^{* * *}$ & 0.0256 & $-0.0807^{*}$ & 0.0468 & $-0.0848^{* * *}$ & 0.0303 \\
\hline Foreign, joint venture & 0.0368 & 0.0277 & 0.0240 & 0.0477 & 0.0328 & 0.0345 \\
\hline shared company & 0.0340 & 0.0283 & 0.0565 & 0.0495 & 0.0006 & 0.0342 \\
\hline other enterprises & -0.2063 & 0.1403 & $-0.4682^{* * *}$ & 0.1528 & 0.1451 & 0.1379 \\
\hline \multicolumn{7}{|c|}{ Firm size: base group $=$ below 8} \\
\hline $8-50$ & $0.0921^{* * *}$ & 0.0192 & $0.0870^{* *}$ & 0.0341 & $0.0925^{* * *}$ & 0.0234 \\
\hline above 50 & $0.1347^{* * *}$ & 0.0200 & $0.1619^{* * *}$ & 0.0354 & $0.1216^{* * *}$ & 0.0241 \\
\hline constant & $0.7124^{* * *}$ & 0.0870 & $0.7912^{* * *}$ & 0.1478 & $0.6458^{* * *}$ & 0.1065 \\
\hline adjust $R^{2}$ & 0.3330 & & 0.3384 & & 0.3283 & \\
\hline $\mathrm{N}$ & 4845 & & 1819 & & 3026 & \\
\hline
\end{tabular}

Note: Dependent variable $=\log$ of hourly wage; SE refers to robust standard error; Provinces controlled. ${ }^{*} p<0.10,{ }^{* *} p<0.05,{ }^{* * *} p<0.01$ 
Table 7: Switching regression: selection model

\begin{tabular}{lcc}
\hline & Coefficient & SE \\
\hline unmarried & $-0.1572^{* * *}$ & 0.0524 \\
non-local rural hukou & $-0.1193^{* * *}$ & 0.0436 \\
ratio of labour migrants in home village & $0.0044^{* * *}$ & 0.0008 \\
age & $-0.0382^{* *}$ & 0.0158 \\
age squared & $0.0528^{* *}$ & 0.0218 \\
years of migration & -0.0139 & 0.0113 \\
years of migration squared & $0.0848^{* *}$ & 0.0426 \\
male & 0.0288 & 0.0395 \\
Education:base group=Junior middle school & \\
Elementary school or blow & $0.1265^{* *}$ & 0.0593 \\
Senior middle school & $-0.1854^{* * *}$ & 0.0443 \\
Specialized secondary school & $-0.4888^{* * *}$ & 0.0519 \\
constant & $0.9628^{* * *}$ & 0.2633 \\
\hline$N$ & 4723 & \\
\hline
\end{tabular}

Note: Dependent variable: dummy $=1$ if user of network.

${ }^{*} p<0.10,{ }^{* *} p<0.05,{ }^{* * *} p<0.01$ 
Table 8: Switching regression: wage equation

\begin{tabular}{|c|c|c|c|c|}
\hline & \multicolumn{2}{|c|}{ non-users of network } & \multicolumn{2}{|c|}{ users of network } \\
\hline & Coefficient & $\mathrm{SE}$ & Coefficient & $\mathrm{SE}$ \\
\hline age & $0.0255^{* * *}$ & 0.0091 & $0.0463^{* * *}$ & 0.0059 \\
\hline age squared & $-0.0412^{* * *}$ & 0.0133 & $-0.0700^{* * *}$ & 0.0084 \\
\hline years of migration & $0.0284^{* * *}$ & 0.0070 & $0.0150^{* * *}$ & 0.0045 \\
\hline years of migration squared & $-0.0615^{* *}$ & 0.0269 & -0.0174 & 0.0161 \\
\hline male & $0.0923^{* * *}$ & 0.0244 & $0.1278^{* * *}$ & 0.0176 \\
\hline years of schooling & $0.0346^{* * *}$ & 0.0052 & $0.0288^{* * *}$ & 0.0036 \\
\hline \multicolumn{5}{|c|}{ Occupation: base group $=$ white collar } \\
\hline Blue collar & $-0.2137^{* * *}$ & 0.0345 & $-0.1376^{* * *}$ & 0.0315 \\
\hline other occupation & -0.0708 & 0.1655 & -0.1754 & 0.1231 \\
\hline \multicolumn{5}{|c|}{ Industry: base group=manufactory } \\
\hline construction & $0.1572^{* * *}$ & 0.0425 & $0.1066^{* * *}$ & 0.0281 \\
\hline $\begin{array}{l}\text { Electricity, gas, water, } \\
\text { transportation and IT }\end{array}$ & -0.0054 & 0.0572 & 0.0506 & 0.0414 \\
\hline Commerce and trade & 0.0254 & 0.0383 & 0.0076 & 0.0280 \\
\hline Restaurants and catering & $-0.1379^{* * *}$ & 0.0348 & $-0.1109^{* * *}$ & 0.0268 \\
\hline $\begin{array}{l}\text { Finance, estate, health, } \\
\text { education, science }\end{array}$ & -0.0250 & 0.0378 & -0.0437 & 0.0295 \\
\hline services & -0.0599 & 0.0393 & $-0.0588^{*}$ & 0.0310 \\
\hline \multicolumn{5}{|c|}{ Ownership: base group=state and collective } \\
\hline Private enterprises & -0.0501 & 0.0399 & -0.0411 & 0.0261 \\
\hline Self-employed Individuals & -0.0595 & 0.0454 & $-0.0902^{* * *}$ & 0.0297 \\
\hline Foreign, joint venture & 0.0411 & 0.0454 & 0.0248 & 0.0349 \\
\hline shared company & 0.0721 & 0.0475 & 0.0024 & 0.0350 \\
\hline other enterprises & $-0.4367^{* *}$ & 0.1797 & 0.1040 & 0.2394 \\
\hline \multicolumn{5}{|c|}{ Firm size: base group $=$ below 8} \\
\hline $8-50$ & $0.0846^{* * *}$ & 0.0321 & $0.0987^{* * *}$ & 0.0223 \\
\hline above 50 & $0.1512^{* * *}$ & 0.0325 & $0.1235^{* * *}$ & 0.0235 \\
\hline constant & $1.2765^{* * *}$ & 0.1733 & $0.5617^{* * *}$ & 0.1073 \\
\hline rho & $0.6613^{* * *}$ & 0.0662 & $0.6227^{* * *}$ & 0.0647 \\
\hline sigma & 0.5107 & 0.0239 & 0.4604 & 0.0144 \\
\hline$R^{2}$ & 0.3614 & & 0.3366 & \\
\hline$N$ & 1765 & & 2958 & \\
\hline
\end{tabular}

Note: Dependent variable $=\log$ of hourly wage; Province controlled.

${ }^{*} p<0.10,{ }^{* *} p<0.05,{ }^{* * *} p<0.01$ 
Table 9: Observed and predicted log hourly wages

\begin{tabular}{llcc}
\hline & & Mean & SD \\
\hline \multirow{3}{*}{ users of network } & observed & 1.6285 & 0.5015 \\
& unconditional & 1.4608 & 0.2784 \\
& conditional on users of network & 1.6286 & 0.2897 \\
& conditional on non-users of network & 2.1705 & 0.3014 \\
\hline \multirow{3}{*}{ non-users of network } & observed & 1.7181 & 0.5317 \\
& unconditional & 2.0490 & 0.2971 \\
& conditional on users of network & 1.2349 & 0.2915 \\
& conditional on non-users of network & 1.7176 & 0.3166 \\
\hline
\end{tabular}

Table 10: Over-identifying test

\begin{tabular}{lcl}
\hline & Coefficient & SE \\
\hline unmarried & -0.0103 & 0.0200 \\
non-local rural hukou & -0.0066 & 0.0184 \\
ratio of labour migrants in home village & -0.0004 & 0.0003 \\
constant & 0.0237 & 0.0267 \\
\hline Adjust $R^{2}$ & -0.0062 & \\
$N$ & 4723 & \\
\hline
\end{tabular}

Note: Dependent variable: residual of wage equation from switching regression.

All variables used in wage equation are controlled.

${ }^{*} p<0.10,{ }^{* *} p<0.05,{ }^{* * *} p<0.01$

Table 11: Wage equations from Treatment effect models: ML and two-steps ML two-steps

\begin{tabular}{|c|c|c|c|c|}
\hline & Coefficient & $\mathrm{SE}$ & Coefficient & $\mathrm{SE}$ \\
\hline users of network & $-0.4380^{* * *}$ & 0.0558 & $-0.5303^{* * *}$ & 0.1131 \\
\hline rho & $0.5705^{* * *}$ & & $0.6631^{* * *}$ & \\
\hline sigma & 0.4662 & & 0.4871 & \\
\hline lambda & 0.2660 & & 0.3230 & \\
\hline$N$ & 4723 & & 4723 & \\
\hline
\end{tabular}

Note: Dependent variable $=\log$ of hourly wage.

Personal characteristics, job characteristics and Province dummies controlled.

${ }^{*} p<0.10,{ }^{* *} p<0.05,{ }^{* * *} p<0.01$ 
Table 12: Observed and predicted log hourly wages

\begin{tabular}{llllll}
\hline & & \multicolumn{2}{c}{ First Jobs holders } & \multicolumn{2}{c}{ People changed Jobs } \\
& & \multicolumn{2}{c}{$\mathrm{N}=2056$} & \multicolumn{2}{c}{$\mathrm{N}=2658$} \\
& & Mean & SD & Mean & SD \\
\hline users of network & rho & $0.5418^{* * *}$ & & $0.6721^{* * *}$ & \\
& sigma & 0.4329 & & 0.4707 & \\
& observed & 1.6269 & 0.5106 & 1.6293 & 0.4937 \\
& unconditional & 1.4993 & 0.3116 & 1.4358 & 0.2667 \\
\hline non-users of network & rho & $0.8838^{* * *}$ & & $0.3047^{*}$ & \\
& sigma & 0.6388 & & 0.4268 & \\
& observed & 1.7607 & 0.5633 & 1.6898 & 0.5086 \\
& unconditional & 2.3477 & 0.3275 & 1.8105 & 0.2892 \\
\hline
\end{tabular}

Note: ${ }^{*} p<0.10,{ }^{* *} p<0.05,{ }^{* * *} p<0.01$ 
Table A.1: Data descriptions (mean or frequencies)

\begin{tabular}{|c|c|c|c|}
\hline & non-users of network & users of network & total \\
\hline age & 29.16 & 30.60 & 30.06 \\
\hline years of migration & 7.73 & 8.34 & 8.11 \\
\hline years of schooling & 9.46 & 8.68 & 8.97 \\
\hline $\begin{array}{l}\text { ratio of labour migrants in } \\
\text { home village }\end{array}$ & 56.46 & 59.38 & 58.28 \\
\hline female & 42.25 & 42.43 & 42.36 \\
\hline male & 57.75 & 57.57 & 57.64 \\
\hline married & 52.99 & 60.01 & 57.38 \\
\hline unmarried & 47.01 & 39.99 & 42.62 \\
\hline local rural hukou & 16.72 & 20.77 & 19.26 \\
\hline non-local rural hukou & 83.28 & 79.23 & 80.74 \\
\hline \multicolumn{4}{|l|}{ Occupation } \\
\hline white collar & 10.87 & 6.25 & 7.98 \\
\hline Blue collar & 83.82 & 89.11 & 87.13 \\
\hline other occupation & 5.31 & 4.64 & 4.89 \\
\hline \multicolumn{4}{|l|}{ Industry } \\
\hline manufactory & 26.71 & 20.95 & 23.10 \\
\hline construction & 8.44 & 14.41 & 12.18 \\
\hline $\begin{array}{l}\text { Electricity, gas, water, } \\
\text { transportation and IT }\end{array}$ & 3.58 & 4.20 & 3.97 \\
\hline Commerce and trade & 17.18 & 19.31 & 18.51 \\
\hline Restaurants and catering & 20.23 & 19.04 & 19.49 \\
\hline $\begin{array}{l}\text { Finance, estate, health, } \\
\text { education, science }\end{array}$ & 12.86 & 11.53 & 12.03 \\
\hline services & 11.00 & 10.56 & 10.73 \\
\hline \multicolumn{4}{|l|}{ Ownership } \\
\hline state and collective & 8.38 & 10.17 & 9.50 \\
\hline Private enterprises & 40.65 & 43.61 & 42.50 \\
\hline Self-employed Individuals & 24.39 & 28.73 & 27.10 \\
\hline Foreign, joint venture & 15.31 & 9.15 & 11.46 \\
\hline shared company & 10.97 & 8.22 & 9.25 \\
\hline other enterprises & 0.30 & 0.12 & 0.19 \\
\hline \multicolumn{4}{|l|}{ Firm size } \\
\hline below 8 & 23.93 & 27.31 & 26.05 \\
\hline $8-50$ & 25.11 & 30.16 & $28.27^{\mathrm{J} 1}$ \\
\hline above 50 & 50.96 & 42.53 & 45.69 \\
\hline
\end{tabular}


Table A.2: Switching regression: selection model

\begin{tabular}{lrc}
\hline & Marginal Effect & SE \\
\hline unmarried & -0.0547 & 0.0236 \\
non-local rural hukou & -0.0594 & 0.0183 \\
ratio of labour migrants in home village & 0.0013 & 0.0004 \\
age & -0.0019 & 0.0016 \\
years of migration & -0.0009 & 0.0021 \\
male & 0.0099 & 0.0154 \\
Education:base group=Junior middle school & & \\
Elementary school or blow & 0.0404 & 0.0237 \\
Senior middle school & -0.0890 & 0.0194 \\
Specialized secondary school & -0.2046 & 0.0218 \\
\hline$N$ & 4723 & \\
\hline Note: Dependent variable: dummy=1 if user of network &
\end{tabular}


Table A.3: Wage equations from Treatment effect models: ML and two-steps

\begin{tabular}{|c|c|c|c|c|}
\hline & \multicolumn{2}{|l|}{ ML } & \multicolumn{2}{|c|}{ two-steps } \\
\hline & Coefficient & $\mathrm{SE}$ & Coefficient & $\mathrm{SE}$ \\
\hline users of network & $-0.4380^{* * *}$ & 0.0558 & $-0.5303^{* * *}$ & 0.1131 \\
\hline age & $0.0403^{* * *}$ & 0.0051 & $0.0401^{* * *}$ & 0.0054 \\
\hline age squared & $-0.0619^{* * *}$ & 0.0074 & $-0.0615^{* * *}$ & 0.0077 \\
\hline years of migration & $0.0185^{* * *}$ & 0.0039 & $0.0183^{* * *}$ & 0.0041 \\
\hline years of migration squared & $-0.0291^{* *}$ & 0.0143 & $-0.0271^{*}$ & 0.0150 \\
\hline male & $0.1113^{* * *}$ & 0.0147 & $0.1118^{* * *}$ & 0.0153 \\
\hline years of schooling & $0.0328^{* * *}$ & 0.0031 & $0.0303^{* * *}$ & 0.0039 \\
\hline \multicolumn{5}{|c|}{ Occupation: base group=white collar } \\
\hline Blue collar & $-0.1781^{* * *}$ & 0.0230 & $-0.1759^{* * *}$ & 0.0231 \\
\hline other occupation & -0.1389 & 0.0985 & -0.1389 & 0.0991 \\
\hline \multicolumn{5}{|c|}{ Industry: base group=manufactory } \\
\hline construction & $0.1156^{* * *}$ & 0.0233 & $0.1131^{* * *}$ & 0.0234 \\
\hline $\begin{array}{l}\text { Electricity, gas, water, } \\
\text { transportation and IT }\end{array}$ & 0.0250 & 0.0337 & 0.0250 & 0.0337 \\
\hline Commerce and trade & 0.0082 & 0.0227 & 0.0065 & 0.0227 \\
\hline Restaurants and catering & $-0.1281^{* * *}$ & 0.0213 & $-0.1281^{* * *}$ & 0.0213 \\
\hline $\begin{array}{l}\text { Finance, estate, health, } \\
\text { education, science }\end{array}$ & $-0.0438^{*}$ & 0.0232 & $-0.0467^{* *}$ & 0.0232 \\
\hline services & $-0.0665^{* * *}$ & 0.0243 & $-0.0657^{* * *}$ & 0.0242 \\
\hline \multicolumn{5}{|c|}{ Ownership: base group=state and collective } \\
\hline Private enterprises & $-0.0450^{* *}$ & 0.0221 & $-0.0456^{* *}$ & 0.0221 \\
\hline Self-employed Individuals & $-0.0770^{* * *}$ & 0.0251 & $-0.0762^{* * *}$ & 0.0251 \\
\hline Foreign, joint venture & 0.0376 & 0.0274 & 0.0357 & 0.0274 \\
\hline shared company & 0.0367 & 0.0280 & 0.0342 & 0.0281 \\
\hline other enterprises & $-0.2643^{*}$ & 0.1430 & $-0.2612^{*}$ & 0.1402 \\
\hline \multicolumn{5}{|c|}{ Firm size: base group $=$ below 8} \\
\hline $8-50$ & $0.0957^{* * *}$ & 0.0184 & $0.0951^{* * *}$ & 0.0184 \\
\hline above 50 & $0.1330^{* * *}$ & 0.0191 & $0.1316^{* * *}$ & 0.0192 \\
\hline constant & $1.0695^{* * *}$ & 0.1014 & $1.1502^{* * *}$ & 0.1333 \\
\hline rho & 0.5705 & & 0.6631 & \\
\hline sigma & 0.4662 & & 0.4871 & \\
\hline lambda & 0.2660 & & 0.3230 & \\
\hline$N$ & 4723 & & 4723 & \\
\hline
\end{tabular}

Note: Dependent variable $=\log$ of hourly wage; Province controlled

${ }^{*} p<0.10,{ }^{* *} p<0.05,{ }^{* * *} p<0.01$ 